\title{
Study of Birch Wood Catalytic Delignification by Hydrogen Peroxide at Atmospheric Pressure
}

\author{
Natalia V. Garyntseva*a, \\ Irina G. Sudakova ${ }^{a}$ and Boris N. Kuznetsov ${ }^{\text {a,b }}$ \\ anstitute of Chemistry and Chemical Technology SB RAS, \\ $50 / 24$ Akademgorodok, Krasnoyarsk, 660049, Russia \\ ${ }^{b}$ Siberian Federal University \\ 79 Svobodny, Krasnoyarsk, 660041, Russia
}

Received 16.06.2015, received in revised form 24.07.2015, accepted 04.08.2015

The influence of conditions of birch wood delignification by hydrogen peroxide in acetic acid -water medium at atmospheric pressure in the presence of $\mathrm{TiO}_{2}$ catalyst on the yield and composition of cellulosic product was studied. It was established that the content of residual lignin in cellulosic product reduces with the increase of $\mathrm{H}_{2} \mathrm{O}_{2}$ and $\mathrm{CH}_{3} \mathrm{COOH}$ concentrations in the reaction medium. Simultaneously there is a decrease in cellulosic product yield.

Keyword: birch wood, delignification, hydrogen peroxide, acetic acid, $\mathrm{TiO}_{2}$ catalyst, cellulosic product, yield, composition.

DOI: $10.17516 / 1998-2836-2015-8-3-422-429$.

(C) Siberian Federal University. All rights reserved

* Corresponding author E-mail address: garyntseva@icct.ru 


\title{
Изучение каталитической делигнификации древесины березы пероксидом водорода при атмосферном давлении
}

\author{
Н.В. Гарынцева ${ }^{a}$, И.Г. Судакова ${ }^{\mathbf{a}}$, Б.Н. Кузнецов ${ }^{\mathrm{a}, \boldsymbol{0}}$ \\ ${ }^{a}$ Институт химии и химической технологии СО РАН \\ Россия, 660036, Красноярск, Академгородок, 50/24 \\ ${ }^{6}$ Сибирский федеральньий университет \\ Россия, 660041, Красноярск, пр. Свободный, 79
}

\begin{abstract}
Изучено влияние условий окислительной делигнификации древесины березы пероксидом водорода в среде разбавленной уксусной кислоты при атмосферном давлении в присутствии катализатора $\mathrm{TiO}_{2}$ на выход и состав целлюлозного продукта. Установлено, что содержание остаточного лигнина в иеллюлозном продукте снижается с ростом концентрации пероксида водорода и уксусной кислоты в реакционной смеси. При этом также наблюдается уменьшение выхода целлюлозного продукта.
\end{abstract}

Ключевые слова: древесина березы, делигнификачия, пероксид водорода, уксусная кислота, катализатор $\mathrm{TiO}_{2}$, иеллюлозный продукт, выход, состав.

\section{Введение}

Большие масштабы производства целлюлозы, основанные на использовании традиционных технологий, приводят ежегодно к попаданию в окружающую среду миллионов тонн серы в виде сероводорода, органических сульфидов, сернистого ангидрида и других вредных соединений.

В этой связи актуальна задача совершенствования методов получения целлюлозы. Одним из перспективных направлений является делигнификация древесины с использованием экологически безопасных окислителей (кислорода и пероксида водорода) и катализаторов [1-7].

Ранее авторами была продемонстрирована возможность ускорения процесса делигнификации древесины в среде «уксусная кислота - пероксид водорода» растворенными катализаторами кислотного $\left(\mathrm{H}_{2} \mathrm{SO}_{4}\right)$ и окислительно-восстановительного типа $\left(\mathrm{Fe}_{2}\left(\mathrm{MoO}_{4}\right)_{3}\right)$, а также твердого катализатора $\mathrm{TiO}_{2}[8-11]$.

Катализаторы способствуют эффективному удалению остаточного лигнина из технических целлюлоз и катализируют окислительную делигнификацию древесины при повышенной температуре $\left(120-140{ }^{\circ} \mathrm{C}\right)$ и давлении.

Береза является одной из основных пород лесов России, но использование древесины березы для получения целлюлозы затруднено из-за ее повышенной плотности и значительного количества гемицеллюлоз. В литературе имеются только отрывочные сведения о применении древесины березы в процессах делигнификации в водно-спиртовых и уксусно-кислых средах.

$$
-423-
$$


Однако установлено [12], что делигнификация древесины березы смесью уксусной кислоты и пероксида водорода в присутствии сернокислотного катализатора при температуре $130{ }^{\circ} \mathrm{C}$ и повышенном давлении приводит к получению целлюлозного продукта с содержанием остаточного лигнина не более $1 \%$ масс.

Осуществлен подбор условий делигнификации древесины осины пероксидом водорода в среде «уксусная кислота - вода» в присутствии сернокислотного катализатора, позволяющих получать целлюлозный продукт с содержанием остаточного лигнина менее 1 \% в мягких условиях (температура $\leq 100^{\circ} \mathrm{C}$, атмосферное давление) $[13,14]$.

Целью данной работы стало изучение возможности осуществления окислительной делигнификации древесины березы пероксидом водорода в мягких условиях в присутствии твердого катализатора $\mathrm{TiO}_{2}$.

\section{Экспериментальная часть}

В качестве исходного сырья использовали древесные опилки (фракция 2,5 - 5 мм) березы повислой (Betulapendula), произрастающей в Красноярском крае. Определение химического состава древесных опилок проводили по стандартным методикам [15]. Содержание основных компонентов древесины березы ( \% масс.): целлюлоза - 46,8; лигнин - 21,7; гемицеллюлозы 27,3; экстрактивные вещества $-3,5 ;$ зола $-0,34$.

Делигнификацию измельченной древесины березы осуществляли в стеклянном реакторе, снабженном механической мешалкой и обратным холодильником. Раствор для делигнификации готовили из смеси ледяной уксусной кислоты, содержание которой варьировали от 15 до $35 \%$ масс., пероксида водорода от 3 до $6 \%$ масс. Значение параметра гидромодуля составляло 5,10 и 15. В качестве катализатора использовали промышленный $\mathrm{TiO}_{2}$ в количестве $1 \%$ масс. от массы древесины. Процесс осуществляли в течение $1-4$ ч при постоянном перемешивании и температуре $70-100{ }^{\circ} \mathrm{C}$.

После делигнификации твердый остаток отделяли от щелока фильтрованием на воронке Бюхнера, промывали до нейтральной реакции промывных вод, высушивали до воздушносухого состояния и анализировали. Содержание лигнина в целлюлозе определяли с использованием 72\%-ной серной кислоты в модификации Комарова, гемицеллюлоз - гидролизом $2 \%$-ной соляной кислотой по методу Макэна и Шоорли [15].

\section{Результаты и обсуждение}

Изучено влияние основных параметров процесса делигнификации древесины березы (температура, продолжительность, гидромодуль, концентрация уксусной кислоты и пероксида водорода) на выход и состав целлюлозного продукта.

Критерием глубины осуществления процесса делигнификации является содержание остаточного лигнина в целлюлозном продукте. Согласно полученным данным (табл. 1), температура и продолжительность процесса значительно влияют на содержание остаточного лигнина в целлюлозном продукте.

При температуре $70-80{ }^{\circ} \mathrm{C}$ после 4 ч проведения процесса не достигается высокая степень делигнификации древесины березы. Целлюлозный продукт содержит 12,7 и 5,4 \% масс. остаточного лигнина соответственно. Повышение температуры до 90-100 ${ }^{\circ} \mathrm{C}$ приводит к резкому 
Таблица 1. Содержание остаточного лигнина и гемицеллюлоз (ГЦ) в целлюлозном продукте древесины березы $\left(\mathrm{CH}_{3} \mathrm{COOH}-25 \%, \mathrm{H}_{2} \mathrm{O}_{2}-5 \%, \Gamma \mathrm{M}-10\right)$.

\begin{tabular}{|c|c|c|c|c|c|}
\hline \multirow{2}{*}{ Температура, ${ }^{\circ} \mathrm{C}$} & \multirow{2}{*}{$\begin{array}{c}\text { Содержание в целлюлозном } \\
\text { продукте, \% масс. }\end{array}$} & \multicolumn{4}{|c|}{ Продолжительность, ч } \\
\cline { 3 - 6 } & $\begin{array}{c}\text { Лигнин } \\
\text { ГЦ }\end{array}$ & 1 & 2 & 3 & 4 \\
\hline \multirow{2}{*}{70} & Лигнин & 9,2 & 14,9 & 14,5 & 12,7 \\
\hline \multirow{2}{*}{80} & $\Gamma Ц$ & 16,6 & 12,5 & 10,5 & 5,4 \\
\cline { 3 - 6 } & Лигнин & 9,2 & 9,0 & 7,6 & 7,4 \\
\hline \multirow{2}{*}{90} & ГЦ & 7,3 & 3,8 & 1,7 & 1,1 \\
\cline { 3 - 6 } & Лигнин & 9,1 & 8,6 & 8 & 5,8 \\
\hline \multirow{2}{*}{100} & ГЦ & 9,5 & 6,5 & 0,7 & 0,8 \\
\cline { 3 - 6 } & & 9,4 & 7,9 & 6,6 & 5,5 \\
\hline
\end{tabular}

снижению содержания остаточного лигнина в целлюлозном продукте. Минимальное количество остаточного лигнина - 0,8 \% масс. - содержится в целлюлозном продукте, полученном делигнификацией древесины березы при $100{ }^{\circ} \mathrm{C}$ в течение 4 ч.

Значительное уменьшение содержания гемицеллюлоз (от 27,3 \% в исходном сырье до 9,1 9,4 \% в целлюлозном продукте) происходит в течение первого часа процесса делигнификации, независимо от температуры. В дальнейшем содержание гемицеллюлоз уменьшается незначительно (до $8,3 \%$ при $70{ }^{\circ} \mathrm{C}$ и $5,5 \%$ при $100{ }^{\circ} \mathrm{C}$ ).

Значительное влияние на содержание лигнина в целлюлозном продукте оказывает начальная концентрация пероксида водорода в растворе (рис. 1). При невысокой начальной концентрации пероксида водорода (3 \% масс.) образуется целлюлозный продукт с повышенным содержанием остаточного лигнина (7,8 \% масс.). Увеличение концентрации $\mathrm{H}_{2} \mathrm{O}_{2}$ до 6 \% масс. приводит к резкому снижению содержания остаточного лигнина в целлюлозном продукте - до 0,5 \% масс. При этом выход целлюлозного продукта снижается с 67,5 до 56,5 \% масс.

Рис. 2 иллюстрирует влияние начальной концентрации уксусной кислоты в реакционной смеси на выход и состав целлюлозного продукта. При содержании уксусной кислоты 15 \% масс. полученный целлюлозный продукт содержит 7,2 \% масс. остаточного лигнина.

Увеличение начальной концентрации уксусной кислоты до 25 \% масс. приводит к снижению содержания лигнина в целлюлозном продукте до 0,8 \% масс. Дальнейшее увеличение содержания уксусной кислоты в растворе до $35 \%$ масс. уменьшает массовую долю остаточного лигнина в продукте до 0,5 \% масс.

Гидромодуль процесса (отношение жидкость / твердое) является важным параметром, позволяющим регулировать выход целлюлозного продукта и содержание в нем остаточного лигнина (рис. 3). При гидромодулях 10 и 15 образуется целлюлозный продукт с низким содержанием остаточного лигнина (0,8 и 0,5 \% масс. соответственно).

Уменьшение величины гидромодуля до 5 увеличивает выход целлюлозного продукта до 70,2 \% масс., но снижает его качество. Вероятно, что высокое содержание лигнина в целлюлозном продукте (9,2 \% масс.) является следствием затруднения диффузии окисляющего реагента в межклеточное пространство и отвода продуктов окисления лигнина в раствор.

$$
-425-
$$




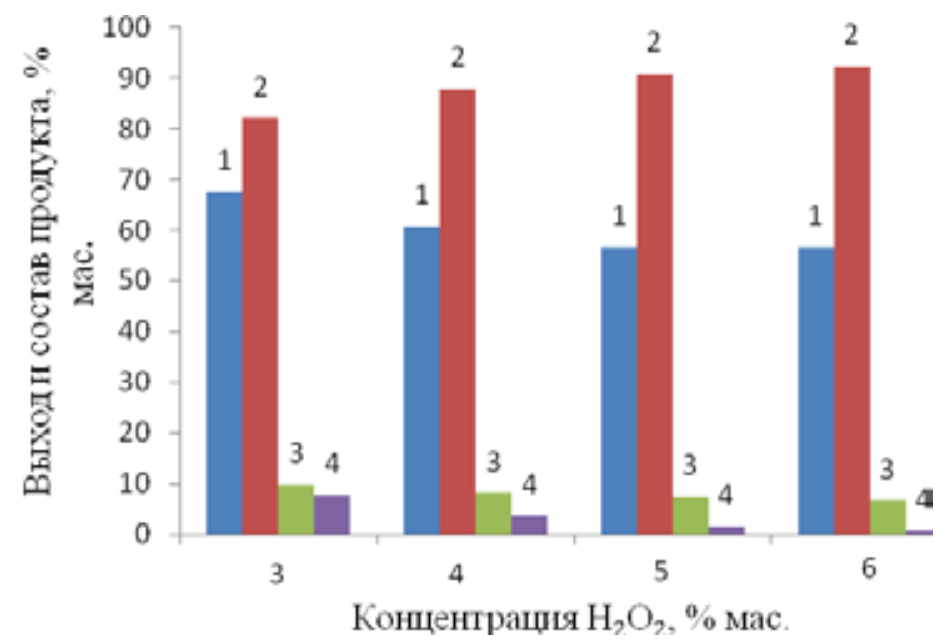

Рис. 1. Влияние концентрации пероксида водорода на выход и состав целлюлозного продукта $\left(\mathrm{CH}_{3} \mathrm{COOH}-\right.$ 25 \% масс., ГМ 10, t - 4 ч): 1 - выход целлюлозного продукта; 2 - содержание целлюлозы; 3 - содержание гемицеллюлоз; 4 - содержание лигнина

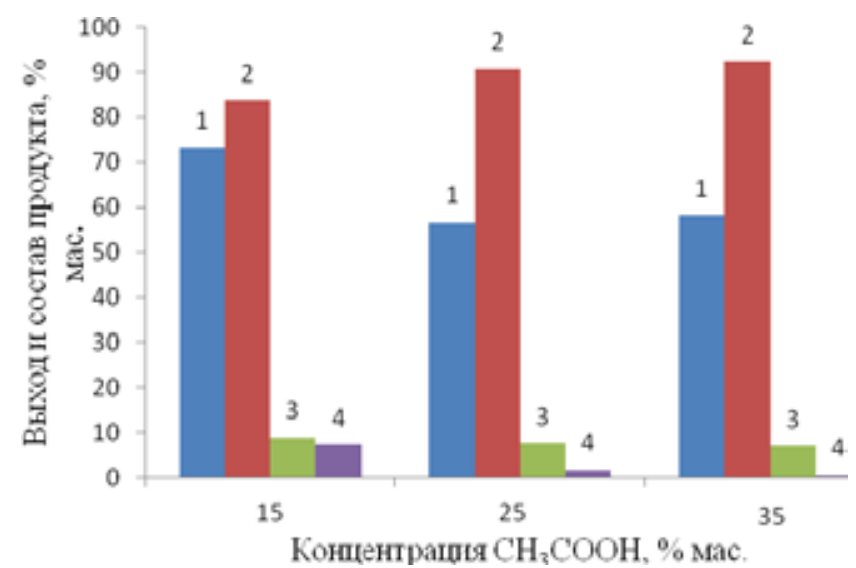

Рис. 2. Влияние концентрации уксусной кислоты на выход и состав целлюлозного продукта $\left(\mathrm{H}_{2} \mathrm{O}_{2}-\right.$ 5 \% масс., ГМ 10, t- 4 ч): 1 - выход целлюлозного продукта; 2 - содержание целлюлозы; 3 - содержание гемицеллюлоз; 4 - содержание лигнина

Для определения основных кинетических параметров - констант скоростей реакции и энергии активации процесса - использовали изменение содержания остаточного лигнина в целлюлозном продукте.

Была изучена динамика изменения содержания остаточного лигнина в целлюлозных продуктах, полученных каталитической делигнификацией древесины березы пероксидом водорода в интервале температур $70-100{ }^{\circ} \mathrm{C}$ (рис. 4).

Ранее было установлено, что процесс делигнификации древесины осины и пихты в среде «уксусная кислота - пероксид водорода - вода, катализатор $\mathrm{H}_{2} \mathrm{SO}_{4}$ » описывается уравнением реакции первого порядка $[13,16]$. 


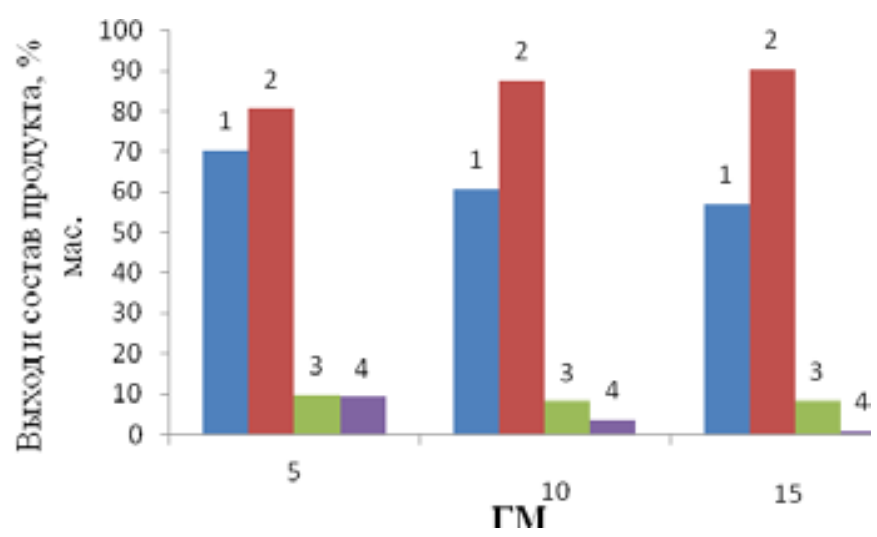

Рис. 3. Влияние гидромодуля процесса окислительной делигнификации древесины березы на выход и состав целлюлозного продукта $\left(\mathrm{CH}_{3} \mathrm{COOH} 25 \%, \mathrm{H}_{2} \mathrm{O}_{2}-5 \%, \mathrm{t}-4\right.$ ч): 1 - выход целлюлозного продукта; 2 - содержание целлюлозы; 3 - содержание гемицеллюлоз; 4 - содержание лигнина

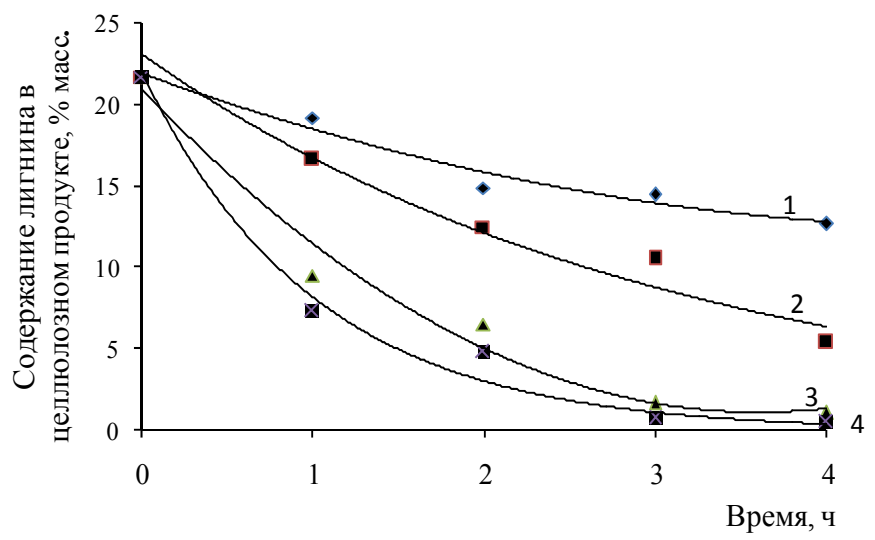

Рис. 4. Влияние продолжительности процесса окислительной каталитической делигнификации древесины березы на содержание остаточного лигнина в целлюлозном продукте: $1-70{ }^{\circ} \mathrm{C} ; 2-80{ }^{\circ} \mathrm{C}$; $3-90{ }^{\circ} \mathrm{C} ; 4-100^{\circ} \mathrm{C}$

Близкий к 1 коэффициент регрессии прямых, полученных при построении зависимость $\operatorname{lnC}$ от времени (рис. 5), указывает на то, что процесс каталитической делигнификации древесины березы в указанных условиях также описывается уравнением первого порядка.

Таким образом, содержание остаточного лигнина в целлюлозном продукте, полученном окислительной делигнификацией древесины березы пероксидом водорода в среде разбавленной уксусной кислоты при атмосферном давлении, в присутствии катализатора $\mathrm{TiO}_{2}$ снижается с повышением концентрации $\mathrm{H}_{2} \mathrm{O}_{2}$ и $\mathrm{CH}_{3} \mathrm{COOH}$ и гидромодуля процесса делигнификации, одновременно наблюдается уменьшение выхода целлюлозного продукта.

В изученных условиях процесс делигнификации древесины березы в среде «пероксид водород - вода - уксусная кислота - катализатор $\mathrm{TiO}_{2}$ » описывается уравнением первого порядка. 


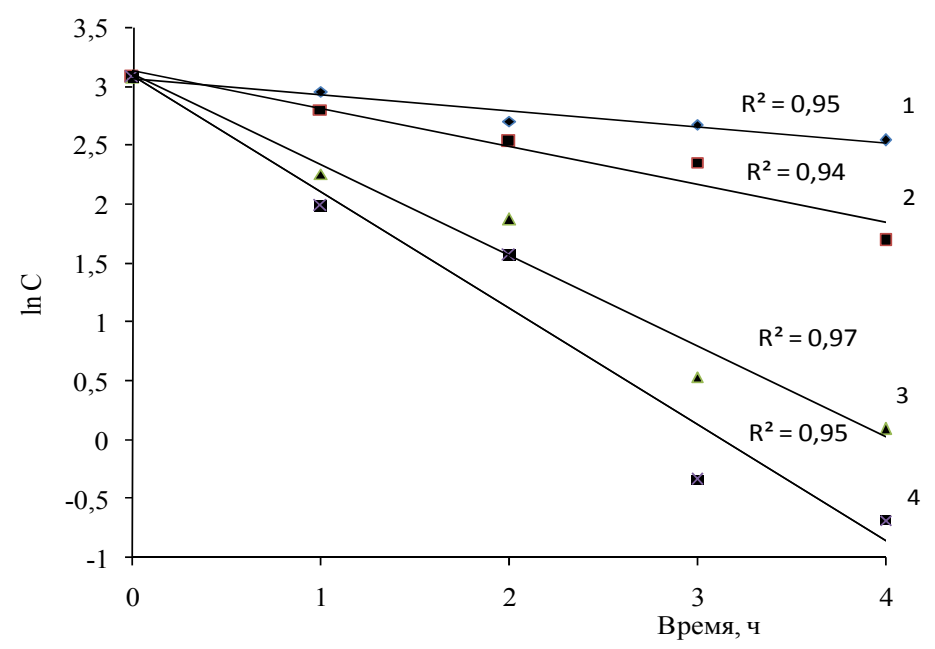

Рис. 5. Зависимость логарифма концентрации лигнина в целлюлозном продукте от продолжительности процесса окислительной каталитической делигнификации древесины березы: $1-70{ }^{\circ} \mathrm{C} ; 2-80{ }^{\circ} \mathrm{C} ; 3-90$ ${ }^{\circ} \mathrm{C} ; 4-100{ }^{\circ} \mathrm{C}$

\section{Благодарности}

Работа выполнена при финансовой поддержке Российского фонда фундаментальных исследований (грант № НК15-53-16015/15).

\section{Список литература}

1. Armindo R. Gaspar, Jose' A. F. Gamelas, Dmitry V. Evtuguin, Carlos Pascoal Neto Alternatives for lignocellulosic pulp delignification using polyoxometalates and oxygen: a review // Green Chem. 2007. Vol. 9. P. 717-730.

2. Suchy M., Argyropoulos D.S. Catalysis and activation of oxygen and peroxide delignification of chemical pulps: a review // Tappi Journal. 2002. Vol. 1(2), P.

3. Lucas M., Hanson S.K., Waqner G.L., Kimball D.B., Rector K.D. Evidence for room temperature delignification of wood using hydrogen peroxide and manganese acetate as a catalyst // Bioresour Technology. 2012. Vol. 119, P. 174-185.

4. Chen C.L., Capanema E.A., Gracz H.S. Comparative studies on the delignification of pine kraft-anthraquinone pulp with hydrogen peroxide by binucleus Mn(IV) complex catalysis // Journal of Agricultural Food Chemistry. 2003. Vol. 51 (21), P. 6223-32.

5. Пен Р.3., Каретникова Н.В. Катализируемая делигнификация древесины пероксидом водорода и пероксикислотами (Обзор) // Химия растительного сырья. 2005. № 3. С. 61-73. [Pеn R.Z., Karetnikova N.V. Catalytic delignification of wood by hydrogen peroxide and peroxyacides (Review). Chemistry of plant raw materials 2005. Vol. 3, P. 61-73. (in Russ.)].

6. Kuznetsov B. N., Taraban'ko V. E., Kuznetsova S. A. New Catalytic Methods for Obtaining Cellulose and Other Chemical Products from Vegetable Biomass. Kinetics and Catalysis 2008.Vol. 49 (4), P. 517-526.

7. Majid Montazer, Somaye Morshedi. Photo bleaching of wood using nanoTiO $\mathrm{O}_{2}$ under daylight irradiation // Journal of Industrial and Engineering Chemistry. 2014. Vol. 20, P. 83-90. 
8. Кузнецов Б.Н., Кузнецова С.А., Данилов В.Г., Яценкова О.В., Александрова Н.Б. Делигнификация древесины осины уксусной кислотой в присутствии пероксида водорода и гетерогенного катализатора $\mathrm{TiO}_{2} / /$ Химия растительного сырья 2007. № 4, C. 21-24. [Kuznetsov B.N., Kuznetsova S.A., Danilov V.G., Yatsenkova O.V., Alexandrova N.B. Delignification of aspen wood by acetic acid in the present hydrogen peroxide and heterogeneous catalyst $\mathrm{TiO}_{2}$. Chemistry of plant raw materials 2007. Vol. 4, P. 21-24. (in Russ.)].

9. Kuznetsov B.N., Kuznetsova S.A., Danilov V.G., Yatsenkova O.V. Catalytic properties of $\mathrm{TiO}_{2}$ in wood delignification by acetic acid - hydrogen peroxide mixture // React. Kinet.Catal. Lett. 2008. Vol. 94 (2), P. 311-317.

10. Kuznetsov B.N., Kuznetsova S.A., Danilov V.G., Yatsenkova O.V. Influence of UV pretreatment on the abies wood catalytic delignification in the medium "acetic acid -hydrogen peroxide - $\mathrm{TiO}_{2} / /$ Reaction Kinetic and Catalysis Letters. 2009. Vol. 97 (2), P. 295-300.

11. Кузнецов Б.Н., Данилов В.Г., Кузнецова С.А., Яценкова О.В., Александрова Н.Б. Оптимизация процесса делигнификации древесины пихты уксусной кислотой в присутствии пероксида водорода и катализатора $\mathrm{TiO}_{2} / /$ Химическая технология 2008. №7. С. 328-332. [Kuznetsov B.N., Danilov V.G., Kuznetsova S.A., Yatsenkova O.V., Alexandrova N.B. Optimization of fir wood delignification by acetic acid in the presence of hydrogen peroxide and catalyst $\mathrm{TiO}_{2}$. Chemical Technology 2008. Vol. 7, Р. 328-332. (in Russ.)].

12. Кузнецова С.А., Данилов В.Г., Яценкова О.В., Иванченко Н.М. Экологически безопасный процесс получения целлюлозы из древесины // Журнал СФУ. Химия. 2008. № 1. С. 80-87. [Kuznetsova S.A., Danilov V.G., Yatsenkova O.V., Ivanchenko N.M. Ecologically Friendly Process of Cellulose Obtaining from Birch Wood. Journal of Siberian Federal University. Chemistry 2008. Vol. 1(1), P.80-87. (in Russ.)].

13. Kuznetsov B.N., Sudakova I.G., Garyntseva N.V., Djakovitch L., Pinel C. Kinetic study of aspen-wood sawdust delignification by $\mathrm{H}_{2} \mathrm{O}_{2}$ with sulfuric acid catalyst under the mild conditions // Reac Kinet Mech Cat. 2013. Vol. 110. P. 271-280.

14. Судакова И.Г., Гарынцева Н.В., Яценкова О.В., Кузнецов Б.Н. Оптимизация процесса делигнификации древесины осины пероксидом водорода в присутствии сернокислотного катализатора // Журнал СФУ. Химия. 2013. № 1. C.76-84. [Sudakova I.G., Garyntseva N.V., Yatsenkova O.V., Kuznetsov B.N. Optimization of Aspen Wood Delignification by $\mathrm{H} 2 \mathrm{O} 2$ with Sulfuric Acid Catalyst. // Journal of Siberian Federal University. Chemistry 2013. Vol. 6 (1), P.76874 (in Russ.)].

15. Оболенская А.В., Ельницкая 3.П., Леонович А.А. Лабораторные работы по химии древесины и целлюлозы. М.: Экология, 1991. 321 с. [Obolenskaya A.V., Yelnitskaya Z.P., Leonovich A.A. Laboratory work on the chemistry of wood and cellulose. M.: Ecology, 1991. 321 pp. (in Russ.)].

16. Кузнецов Б.Н., Судакова И.Г., Гарынцева Н.В, Иванченко Н.М. Делигнификация древесины пихты пероксидом водорода в мягких условиях в присутствии сернокислотного катализатора // Журнал СФУ. Химия. 2013. № 4. С. 361-371. [Kuznetsov B.N., Sudakova I.G., Garyntseva N.V, Ivanchenko N.M. Abies Wood Delignification by Hydrogen Peroxide at Mild Conditions in the Presence of Sulfuric Acid Catalyst. Journal of Siberian Federal University. Chemistry 2013. Vol. 6 (4), P. 361-371 (in Russ.)]. 